\title{
Sex Differences in Short-term Mate Preferences and Behavioral Mimicry: A Semi-Naturalistic Experiment
}

\author{
Ischa van Straaten · Rutger C. M. E. Engels • \\ Catrin Finkenauer $\cdot$ Rob W. Holland
}

Received: 8 May 2006/Revised: 16 November 2006/Accepted: 25 November 2006/Published online: 8 August 2007

(C) Springer Science+Business Media, LLC 2007

\begin{abstract}
Studies on short-term mating (STM) yield sex differences regarding preferences for attractiveness (important to women, very important to men) and social status (very important to women, not to men) in potential mates. Additionally, men generally report a greater desire to engage in STM than women. So far, this evidence is primarily based on studies using vignettes or surveys. The current study extended the findings on sex differences in STM by examining actual behavior and STM-desires towards real people of the opposite sex. It investigated whether (1) sex differences exist in STM-desire, (2) whether this desire was affected by a confederate's attractiveness and status, and (3) if these sex differences were also reflected in interpersonal behavior (mimicry). In a pub-like laboratory, single heterosexual participants performed a task alongside a confederate of the opposite sex, who differed in attractiveness and social status. Mimicry was observed and explicit STM-desire was assessed. Results showed that men only desired STM more than women in the case of an attractive partner. Women's STMdesire did not vary as a function of status or attractiveness of the potential partner. Men's, but not women's, mimicry paralleled these differential STM-desires. These results underline the conditionality of sex differences in STM-desire and provide a useful paradigm to further investigate STM.
\end{abstract}

I. van Straaten $(\bowtie) \cdot$ R. C. M. E. Engels · R. W. Holland Behavioural Science Institute, Radboud University Nijmegen, P. O. Box 9104, Nijmegen 6500 HE, The Netherlands e-mail: I.vanStraaten@bsi.ru.nl

C. Finkenauer

Department of Social Psychology, Vrije Universiteit, Amsterdam, The Netherlands
Keywords Short-term mating - Naturalistic environment . Attractiveness $\cdot$ Social status $\cdot$ Mimicry

\section{Introduction}

Contemporary media seem preoccupied with so-called social experiments, such as Big Brother. Among these, a specifically popular genre turns the TV audience into voyeuristic witnesses of human mating processes. Viewing figures suggest that the audience loves to watch others get involved in situations that concern purely sexual relations. Short-term mating (STM) has also received growing attention from scientists, in particular since the introduction of sexual strategies theory (Buss \& Schmitt, 1993). Sexual strategies theory posits that women and men differ in their desire to engage in STM (men more than women) and in their preference for either physically attractive (important to both sexes, but more to men than women) or high-status partners (important to women only). Confirming evidence for these hypotheses has been found, but contrasting findings are reported as well. To overcome some methodological issues that might explain the contradictory findings, we took a different approach, focusing on desire towards real potential partners and observing interpersonal behavior.

\section{Evolution of the desire for STM}

Evolutionary psychologists generally agree on the adaptive function that STM has for single men. The evolutionary perspective holds that men who strive for sexual intercourse without relational commitment have a larger maximum number of offspring than men who aim for just one life-time partner (Buss \& Schmitt, 1993; Symons, 1979; Trivers, 
1972). Therefore, it is hypothesized that single men will desire STM to a great extent. For women, however, the story is more complicated, because sexual encounters hold great risks for them (violence) and, more importantly, the possible pregnancy has more extreme consequences for women than for men (see Trivers, 1972 parental investment theory). These risks are considered to make women more reluctant to engage in STM.

Indeed, evidence shows that compared to women, men seek a short-term mate more strongly and report more favorable attitudes towards STM (Buss \& Schmitt, 1993; Herold \& Mewhinney, 1993; Oliver \& Hyde, 1993; Roche, 1986). Men also report more casual sex partners (Baldwin \& Baldwin, 1988; Laumann, Gagnon, Michael, \& Michaels, 1994; Townsend, 1995; Traeen \& Lewin, 1992) and are more receptive to sexual offers than women (Clark, 1990; Clark \& Hatfield, 1989; Greitemeyer, 2005). However, several researchers have noted that it is statistically impossible to have a gender gap between male and female numbers of heterosexual STM-partners (Baumeister, Catanese, \& Vohs, 2001; Brown \& Sinclair, 1999; Pedersen, Miller, Putcha-Bhagavatula, \& Yang, 2002; Wiederman, 1997). Several recent studies support this notion, showing that the gender gap in number of STM-partners is not as universal and robust as previously stated (e.g., Cubbins \& Tanfer, 2000; Johnson et al., 2001).

What then are potential adaptive benefits for single women to engage in STM? The two most important possible benefits for single women are considered the direct obtainment of resources (e.g., money, food, jewelry) and the assessment and evaluation of potential long-term mates (Buss \& Schmitt, 1993; Gangestad \& Simpson, 1990; Greiling \& Buss, 2000; Shackelford, Goetz, LaMunyon, Quintus, \& WeekesShackelford, 2004; Symons, 1979). A third hypothesized benefit for single women is considered the acquisition of "good genes" for healthy and attractive offspring (Smith, 1984; Symons, 1979). ${ }^{1}$ Interestingly, these three hypotheses (resource accrual hypothesis, mate assessment hypothesis, and good genes hypothesis) lead to predictions about female STM-preferences for physical attractiveness and social status, which we will discuss next.

\section{Evolution of STM preferences}

Considering the differential adaptive functions STM appears to have for single men and women, in what way could these be reflected in sex-similar preferences for

\footnotetext{
1 Additional benefits of STM have been hypothesized (including the paternity confusion hypothesis, Hrdy, 1981; for other examples, see also Symons, 1979) in the context of extra-pair mating (for an overview, see Greiling \& Buss, 2000). However, for the current study, we will only focus on casual sex among single women and men.
}

certain characteristics in their mate? Because for men the adaptive function of STM lies in maximizing their number of offspring, they are hypothesized to prefer mates who are physically attractive, thus signaling high fertility and good genes (Buss \& Schmitt, 1993). However, to some extent, men seem willing to compromise on this precondition (e.g., Regan, 1998). For women, the resource accrual hypothesis, mate assessment hypothesis, and good genes hypothesis predict that both physical attractiveness and social status are of importance in a short-term mate (Buss \& Schmitt, 1993; Gangestad \& Simpson, 1990). That is, attractiveness of the man is predictive of healthy offspring in case the mate becomes a long-term mate and in case of direct pregnancy. Further, social status is associated with increased earning capacities, which is useful with regard to both direct and future resources.

Although not many experimental or survey studies on STM-preferences of single men and women have been conducted, some have supported the posed hypotheses. Townsend and Wasserman (1998) used an experimental design in which participants read vignettes depicting targets that varied in attractiveness accompanied by varied levels of status or income related descriptions. They found that, when comparing both sexes, men preferred physical attractiveness more and women preferred high status. Furthermore, both men and women preferred physically attractive mates to less attractive mates in the context of STM as opposed to longterm mating (see also Townsend \& Levy, 1990). Similar results were obtained in several survey studies (Buss \& Schmitt, 1993; Gangestad \& Simpson, 2000).

Importantly, survey and vignette studies have also obtained results that are incompatible with the evolutionbased predictions of sex differences in preferences. For example, several reports have highlighted the similarity between men and women in their preferences for highly attractive or high status short-term mates, using both surveys and vignettes (Regan, 1998; Regan \& Dreyer, 1999; Sprecher \& Regan, 2002). Additionally, Wiederman and Dubois (1998), who used both ratings and vignettes with multiple manipulated characteristics, showed that although women, as compared to men, attached more importance to the ability of a short-term mate to provide resources, these importance ratings did not predict their actual STM-choices. This suggests that the frequently found sex difference in preferences for characteristics is not indicative of the assumed innate preferences. However, we will try to explain these conflicting results from a methodological perspective.

\section{Methodological issues}

The most important problem many studies on mate preferences face concerns the poor external validity. Comparisons 
of the dependent measures in the described studies with the occurrence of actual behavior cannot easily be made. First, targets in vignette-studies typically lack realism, and "may not be representative of potential short-term mates in the 'real world'" (Wiederman \& Dubois, 1998, p. 166). So, participants depend on minimal information, which forces them to use their imagination. In turn, this stimulates the incorporation of earlier experiences and fantasies into the vignette and activates normative scripts that are associated with these vignettes. Second, the laboratory settings in which many experiments are conducted might evoke responses that are very different from responses in real-life situations. The artificial laboratory activates certain behavioral mechanisms. That is, the context might create an ambiguous situation, in which people typically act as they assume other people would do. Taken together, these aspects of the use of vignettes and non-natural laboratories make participants' responses liable to social desirability influences.

So, how can we overcome the problems of internal and external validity? As far as external validity is concerned, experimental studies about mating preferences should include real-life targets. The experience of meeting the actual person would add to the realism of questions about desires. These inner drives are existent and can be truly felt instead of anticipated. There are a few studies that investigated the influence of physical attractiveness on opposite-sex interactions (e.g., Berry \& Miller, 2001; Garcia, Stinson, Ickes, Bissonnette, \& Briggs, 1991). However, these studies randomly paired participants with one another, resulting in diverse and incomparable situations, and STM-desire was never assessed. In addition, external validity would particularly benefit from the use of naturalistic environments (see, for example, Maxwell, Cook, \& Burr, 1985), in which the behavior of interest typically occurs, instead of the usual artificial laboratory (Rocheleau, Webster, Bryan, \& Frazier, 2004)

To increase internal validity, the problem of social desirability could be partly tackled by reducing participants' awareness of which behaviors exactly are being investigated (Webb, Campbell, Schwartz, \& Sechrest, 1966). We believe an unobtrusive observational approach provides conditions to do so. It is essential to create a context in which participants are not requested to think deliberately about their own preferences. A well-known example of one of the few observational studies on sex differences in sexual behavior is the study by Clark and Hatfield (1989; for a replication, see Clark, 1990). They asked a class of undergraduate students to individually approach unfamiliar opposite-sex students on campus and request them to have sex with them the same night. The results were intriguing, because the majority of the men complied, whereas none of the women did. However, in this study, there was no control or manipulation of the characteristics of the requesters. Hence, it does not address the possible influence of characteristics, such as physical attractiveness and social status, on the desire of men and women. To our knowledge, so far no attempts have been made to investigate this question using observations of behavior towards non-fictional targets (for a vignette approach, see Greitemeyer, 2005).

We were also interested whether men and women display non-verbal cues that are indicative of their STM-desire. The proposed use of observations provides an opportunity to investigate non-verbal behavior that is automatic and uncontrollable, such as mimicry. ${ }^{2}$ Mimicry is positively correlated with interpersonal liking (Bernieri \& Rosenthal, 1991; LaFrance, 1979) and is used in interpersonal contexts to increase affiliation (Lakin \& Chartrand, 2003). Mimicry generally occurs without awareness and is difficult to verbalize (Chartrand \& Bargh, 1999) and is therefore influenced less by social desirability processes. Mimicry can thus provide additional evidence for sex differences in STMdesire and preferences.

\section{Current study}

In the current study, we investigated whether single men and women differ in their desire to engage in STM with a person they have just met. More specifically, we examined the moderating role physical attractiveness and social status of this person had on the participants' STM-desire and subsequent mimicking behavior. To answer these questions, we conducted an observational experiment, in which single participants performed a task with opposite-sex confederates varying in physical attractiveness and social status. In contrast with previous studies, we created a naturalistic social environment (a pub). Furthermore, we used unobtrusive measures by having participants perform a task that limited verbal interaction, but would allow mimicry of nonverbal behavior. We observed acts of postural and behavioral mimicking. Afterwards, self-report measures of STMdesire ("having sex" and "going on a date") were assessed.

We expected, in line with sexual strategies theory, men to report more STM-desire toward a more attractive woman than toward a less attractive woman, and we expected to find a corresponding increase in the frequency of mimicking behavior. For women a similar, but smaller, effect of attractiveness on STM-desire was expected (good genes hypothesis). In addition, we expected women to report more STM-desire toward a high status as compared to a low status man (resource acquisition hypothesis and mate assessment hypothesis). Female mimicking behavior was expected to show corresponding patterns.

\footnotetext{
2 The term "mimicry" is defined here as "one individual doing what another individual does," which is also referred to in the literature by "imitation".
} 


\section{Method}

Participants

A total of 119 single undergraduate students (all white) participated, of whom 59 were women $(M$ age $=20.50$ years, $S D=2.30)$ and 60 were men $(M$ age $=21.19$ years, $S D=$ 2.68). The participants received course credits or payment $(7 €)$ in exchange for their participation.

\section{Design and procedure}

The experiment consisted of a session in which the participant interacted with a confederate of the opposite sex. A randomized $2(\mathrm{Sex}) \times 2$ (Attractiveness) $\times 2$ (Status) factorial design was used in which attractiveness and social status of the confederate were manipulated.

To create a natural setting for the interaction, the experiment took place in a so-called "bar-lab". In this bar-lab, a real counter and bar stools were present, as well as tables surrounded by chairs and a couch. A billiard table, a table soccer game, and several beer- and movie-posters on the wall functioned to enhance the credibility of the room. The lights were low and a stereo set played popular music during the first minutes. Previous experiments in the same laboratory showed very natural behavioral patterns; people feel at ease quickly and display the same behavior as in normal bars (see, for example, Bot, Engels, \& Knibbe, 2005). Interactions were recorded with unobtrusive video cameras.

Participants were informed that the experiment was conducted for an advertising agency interested in psychological processes while watching commercials. Therefore, they were about to watch and evaluate commercials, while a camera would record their facial expressions. The experimenter explained that this session would be completed with one other person, who was in fact the confederate. We paired participants with a confederate of the opposite sex, who was either High-Attractive or Low-Attractive.

Social Status was manipulated by assigning a high or low status job on the side to the confederate ("research assistant of a full professor" or "employee at a campsite," respectively). A preliminary study with 40 undergraduate students was conducted to validate the status manipulation. Statusrelated associations (ambition and future salary ${ }^{3}$ ) of a fictional opposite-sex person with one of both jobs were rated

\footnotetext{
3 Social status in Western society is composed of several other attributes, in particular socioeconomic status (SES), and current financial resources. Because the distribution of these attributes among student populations is highly skewed, social status evaluations among students are less likely influenced by deviations from the common level (high SES and low financial resources). We chose to manipulate indications of ambition and future resources, because these are more
}

on a scale ranging from 1 (little) to 7 (a lot). A $2(\mathrm{Sex}) \times 2$ (Status: High versus Low) analysis of variance (ANOVA) revealed main effects for Status for both ambition and future salary ratings, respectively, $F(1,37)=21.61, p<.001$, and $F(1,37)=6.20, p<.05$. A research assistant of the full professor was perceived as having more ambition $(M=5.45$, $S D=.89)$ than an opposite-sex employee at a campsite $(M=4.24, S D=1.14)$, and anticipated to earn a higher future salary $(M=4.85, S D=.99$ vs. $M=3.95, S D=1.20)$.

We informed the participant of the confederate's job with the following procedure. Before entering the bar-lab where the confederate was already present, participants completed out a consent form and a form with some questions on personal details. On this form, answers allegedly provided by the other participant were present. One question concerned the participants' job on the side. Above the line where the participant had to state his or her job, the answer of the confederate clearly stated either research assistant of the full professor or employee at a campsite.

After completing the forms, the experimenter instructed the participant to enter the bar-lab and take a seat in front of the counter. In the room, where light background music was played, the confederate introduced him- or herself to the participant. The confederate went to one of the two stools at the counter and the participant sat down on the remaining stool. The experimenter then entered the room and explained shortly that they were about to watch $13 \mathrm{com}$ mercials for $20 \mathrm{~min}$ and complete an evaluation form after each commercial. The experimenter offered the participants drinks, handed them a booklet containing evaluation forms and a pencil, then turned on the video in front of them, and left the room. A few seconds prior to a new commercial, a short buzzing sound indicated the participant and confederate to finish evaluating immediately. With two video cameras (front and back), the entire session was recorded.

The confederates were carefully instructed and subsequently trained not to take initiative in the interaction but to react naturally to remarks and questions from the participant. To prevent the situation from becoming unnatural, the confederates did express normal human interpersonal behavior on two occasions. Besides the personal introduction after the entrance of the participant, the confederates were instructed to seek eye contact and smile briefly at the participant after the fourth commercial, which was very funny. The topics of the other 12 commercials were on slightly negative (aspirin) to slightly positive (candy) subjects. The confederates were also instructed to play for $10 \mathrm{~s}$ with their pencils every other commercial, resulting in six pen playing behaviors per

Footnote 3 continued

probable to distinguish between high and low social status among students and are relevant for reproductive success. 
session. No detailed instruction was given to the confederates with regard to the specific posture that they had to adapt, so they would not feel physically uncomfortable during the task. The instructions did mention that their posture should be open (no clear isolation of his or her personal space, like crossing both arms) and not oriented away from the participant. We also instructed the confederates to naturally change their posture every now and then, but told to be neither too stiff nor restless.

After the last commercial, the experimenter entered again and led the participant to the adjacent room to complete some final questionnaires. Several questions about the commercials were asked (likeability, experience while watching, memory, etc.), followed by the evaluation of the confederate. The session took about $45 \mathrm{~min}$ in total. Afterwards, participants were asked what they thought was the goal of the experiment, thanked and received payment. Debriefing took place after the data collection for the total experiment was completed. At this point, participants could withdraw from the study, which none of the participants did.

\section{Confederates}

Six male and four female confederates were selected out of a pool of persons who replied to a general request for assistance in an experiment about facial expressions. Pictures were taken of their faces, while expressing different kinds of emotions, including a neutral expression. The pictures depicting the confederates with a neutral expression were subsequently rated on physical attractiveness by a group of 60 undergraduate students from a different city in The Netherlands. This minimized the chance of raters and targets to be acquainted. Attractiveness was rated on a scale from 1 to 10 . Of the finally selected confederates, the 30 female students rated the three "High-Attractiveness" men as being more attractive $(M=6.29, S D=1.11)$ than the three "LowAttractiveness" men $(M=3.1, S D=1.29), t(29)=14.53$, $p<.001$. The male students rated the finally selected two "High-Attractiveness" women as being more attractive ( $M=$ $6.19, S D=.99)$ than the two "Low-Attractiveness" women $(M=3.90, S D=1.58), t(29)=12.50, p<.001$.

\section{Measures}

\section{STM-desire}

Two questions measured the participants' perception of the suitability of the confederate as a short-term mate. The questions were "Would you want to go out on a date with $X$ ?", and "Would you go to bed with X?". Response options ranged from 1 (absolutely not) to 7 (absolutely). An additional "no answer" possibility was provided in case participants did not feel comfortable answering these personal questions. No participant chose this option. Participants were prepared for these intimate questions by stressing the personal character of the subsequent questions and emphasizing the anonymity of their answers.

\section{Mimicry}

Two independent raters coded the imitative behavior displayed by the participants. These trained raters were masked to the aim of the study and the hypotheses tested. Frequencies of the particular behaviors were obtained for the entire commercial evaluation task. Imitation of pen playing was defined as the repetitive moving (wiggling) of the pen starting within $10 \mathrm{~s}$ after the confederate started the pen playing, which occurred six times in the entire session (range, 0-6). Posture imitation was defined as adapting an exact or mirrored posture within $10 \mathrm{~s}$ after a change in the confederate's posture (range varied per session). Posture changes consisted of transitions from one fixed posture to another, such as from one arm supporting the head to one hand holding the other. To asses the inter-rater reliability, 25 randomly sampled cases were coded by both raters (Grammer, 1990). Both raters agreed for $77 \%$ for posture change (range, $56 \%$ to $96 \%$ per commercial) and $72 \%$ for pen playing (range, $56 \%$ to $96 \%$ per commercial), indicating sufficient inter-rater reliability.

\section{Results}

Ten participants were omitted from the data for different reasons. Two participants reported suspicion about the goal of our experiment. Three participants had a homosexual orientation. Two participants had met the confederate at an earlier occasion. Finally, the data of three others were lost because of technical failures. This left a total of 109 participants of whom 53 were women and 56 were men.

\section{STM-desire}

Table 1 shows the mean ratings for the two desire ratings as a function of participant's sex, attractiveness, and status. A 2 (Sex of Participant) $\times 2$ (Attractiveness: High versus Low $) \times$ 2 (Status: High versus Low) MANOVA was performed with "date" and "have sex" ratings as dependent variables. Test results are presented in Table 2. For the desire to date, a main effect of Attractiveness was qualified by a Sex $\mathrm{x}$ Attractiveness interaction. Planned comparisons showed that the effect of attractiveness was larger for men, $F(1$, 
$107)=67.27, p<.001$ than for women, $F(1,107)=4.41$, $p<.05$. Additionally, in the low attractiveness condition, men desired to date the confederate less then women, $F(1$, $107)=7.06, p<.05$. In contrast, in the high attractiveness condition, men's date ratings were marginally higher than women's, $F(1,107)=3,78, p=.055$.

Comparable effects were found for the desire to have sex with the confederate. We found main effects of Sex and Attractiveness qualified by a Sex $\times$ Attractiveness interaction. Men in the high attractiveness condition were more willing to have sex compared to the low attractiveness condition, $F(1,107)=55.03, p<.001$. Women in the high attractiveness condition, however, did not show this preference in comparison to women in the low attractiveness condition, $F<1$. Interestingly, whereas men, compared to women, reported a higher level of desire to have sex in the high attractiveness condition, $F(1,107)=27.54, p<.001$, a sex difference was absent in the low attractiveness condition, $F<1$. Unexpectedly, an Attractiveness $\times$ Status interaction was found. The relatively greater desire to have sex with the confederate in the high attractiveness condition in comparison to the low attractiveness condition was even more pronounced when status was high, $F(1,107)=28.48$, $p<.001$, than when status was low, $F(1,107)=3.98, p<$ .05. Additionally, in the high status condition participants reported a higher level of desire to have sex with the confederate than in the low status condition, but only when attractiveness was high, $F(1,107)=4.90, p<.05$ vs. $F<1$.

\section{Mimicry}

Table 3 shows the mean frequencies for both "imitation" variables. Univariate ANOVA's were performed on the frequency of imitation of pen playing and posture change, with Sex, Status, and Attractiveness as between subject factors. Table 4 reports these analyses.

Table 1 Means and SDs of desire to go on a date and to have sex with target as a function of condition (attractiveness and status of the target) and participant's sex

\begin{tabular}{|c|c|c|c|c|c|c|c|c|c|c|c|c|}
\hline \multirow[b]{3}{*}{ Condition } & \multicolumn{6}{|l|}{ Date } & \multicolumn{6}{|c|}{ Have sex } \\
\hline & \multicolumn{2}{|c|}{$\operatorname{Men}(n=56)$} & \multicolumn{2}{|c|}{ Women $(n=53)$} & \multicolumn{2}{|c|}{ Combined $(n=109)$} & \multicolumn{2}{|c|}{ Men $(n=56)$} & \multicolumn{2}{|c|}{ Women $(n=53)$} & \multicolumn{2}{|c|}{ Combined $(n=109)$} \\
\hline & $M$ & $S D$ & $M$ & $S D$ & $M$ & $S D$ & $M$ & $S D$ & $M$ & $S D$ & $M$ & $S D$ \\
\hline \multicolumn{13}{|c|}{ Low attractiveness } \\
\hline Low status & 2.08 & 1.16 & 3.14 & 1.41 & 2.65 & 1.38 & 2.00 & 1.35 & 2.36 & 1.34 & 2.19 & 1.33 \\
\hline High status & 1.94 & 1.06 & 3.15 & 1.68 & 2.48 & 1.48 & 1.75 & 1.24 & 2.08 & 1.19 & 1.90 & 1.21 \\
\hline Combined & 2.00 & 1.09 & 3.15 & 1.51 & 2.56 & 1.42 & 1.86 & 1.27 & 2.22 & 1.25 & 2.04 & 1.26 \\
\hline \multicolumn{13}{|c|}{ High attractiveness } \\
\hline Low status & 4.77 & 1.30 & 3.54 & 1.27 & 4.15 & 1.41 & 4.54 & 1.51 & 1.85 & 1.07 & 3.19 & 1.88 \\
\hline High status & 5.07 & 1.28 & 4.69 & 1.11 & 4.89 & 1.20 & 5.07 & 1.49 & 3.23 & 1.88 & 4.21 & 1.89 \\
\hline Combined & 4.93 & 1.27 & 4.11 & 1.31 & 4.54 & 1.34 & 4.82 & 1.49 & 2.54 & 1.65 & 3.72 & 1.94 \\
\hline
\end{tabular}

Note: Response options ranged from 1 (absolutely not) to 7 (absolutely)

Table 2 Multivariate analysis of variance of desire to go on a date and to have sex

\begin{tabular}{|c|c|c|c|c|c|c|c|}
\hline \multirow[t]{2}{*}{ Source } & \multicolumn{4}{|c|}{ Date } & \multicolumn{3}{|l|}{ Have sex } \\
\hline & df & $F$ & $\eta^{2}$ & $p$ & $F$ & $\eta^{2}$ & $p$ \\
\hline Sex participant (SP) & 1 & $<1$ & 0 & ns & $12.79 * *$ & .11 & .01 \\
\hline Attractiveness (A) & 1 & $60.84 * * *$ & .38 & .001 & $36.53 * * *$ & .27 & .001 \\
\hline Status (S) & 1 & 1.76 & .02 & ns & 1.65 & .02 & ns \\
\hline $\mathrm{SP} \times \mathrm{A}$ & 1 & $15.26 * * *$ & .13 & .001 & $23.51 * * *$ & .19 & .001 \\
\hline $\mathrm{SP} \times \mathrm{S}$ & 1 & 1.04 & .01 & ns & $<1$ & .01 & ns \\
\hline $\mathrm{S} \times \mathrm{A}$ & 1 & 2.55 & .03 & ns & 5.16 & .05 & .03 \\
\hline $\mathrm{S} \times \mathrm{SP} \times \mathrm{A}$ & 1 & $<1$ & .01 & ns & $<1$ & .01 & ns \\
\hline$P$ within-group error & 101 & (1.67) & & & $(1.95)$ & & \\
\hline
\end{tabular}

Note: Values enclosed in parentheses represent mean square errors; $P=$ participants

$* * p<.01, * * * p<.001$ 
Table 3 Mean frequency and SDs of "imitative" behaviors as a function of condition (attractiveness and status of the target) and participant's sex

\begin{tabular}{|c|c|c|c|c|c|c|c|c|c|c|c|c|}
\hline \multirow[b]{3}{*}{ Condition } & \multicolumn{6}{|c|}{ Pen playing } & \multicolumn{6}{|c|}{ Posture change } \\
\hline & \multicolumn{2}{|c|}{ Men $(n=56)$} & \multicolumn{2}{|c|}{ Women $(n=53)$} & \multicolumn{2}{|c|}{ Combined $(n=109)$} & \multicolumn{2}{|c|}{$\operatorname{Men}(n=56)$} & \multicolumn{2}{|c|}{ Women $(n=53)$} & \multicolumn{2}{|c|}{ Combined $(n=109)$} \\
\hline & $M$ & $S D$ & $M$ & $S D$ & $M$ & $S D$ & $M$ & $S D$ & $M$ & $S D$ & $M$ & $S D$ \\
\hline \multicolumn{13}{|c|}{ Low attractiveness } \\
\hline Low status & 1.17 & 1.03 & .29 & .61 & .69 & .93 & .33 & .44 & 1.04 & .97 & .71 & .84 \\
\hline High status & 1.13 & 1.31 & 1.15 & 1.14 & 1.14 & 1.22 & .25 & .45 & .77 & 1.07 & .48 & .82 \\
\hline Combined & 1.14 & 1.18 & .70 & .99 & .93 & 1.10 & .29 & .44 & .97 & 1.01 & .59 & .83 \\
\hline \multicolumn{13}{|c|}{ High attractiveness } \\
\hline Low status & 1.54 & 1.71 & .54 & .97 & 1.04 & 1.46 & 1.04 & 1.36 & .35 & .55 & .69 & 1.08 \\
\hline High status & .73 & 1.58 & 1.62 & 1.89 & 1.14 & 1.76 & 1.10 & 1.27 & .58 & .95 & .86 & 1.15 \\
\hline Combined & 1.11 & 1.66 & 1.08 & 1.57 & 1.09 & 1.61 & 1.07 & 1.29 & .46 & .77 & .78 & 1.11 \\
\hline
\end{tabular}

Note: Frequencies ranged from 0 to 6 for Pen Playing and varied per session for Posture Change

Table 4 Univariate analysis of variance of "imitative" behaviors

\begin{tabular}{|c|c|c|c|c|c|c|c|}
\hline \multirow[t]{2}{*}{ Source } & \multicolumn{4}{|c|}{ Pen playing } & \multicolumn{3}{|c|}{ Posture change } \\
\hline & df & $F$ & $\eta^{2}$ & $p$ & $F$ & $\eta^{2}$ & $P$ \\
\hline Sex Participant (SP) & 1 & $<1$ & .01 & $\mathrm{~ns}$ & $<1$ & 0 & ns \\
\hline Attractiveness (A) & 1 & $<1$ & 0 & ns & $<1$ & .01 & ns \\
\hline Status (S) & 1 & 1.13 & .01 & ns & $<1$ & 0 & ns \\
\hline $\mathrm{SP} \times \mathrm{A}$ & 1 & $<1$ & .01 & ns & $11.18 * * *$ & .1 & .001 \\
\hline $\mathrm{SP} \times \mathrm{S}$ & 1 & $7.29 * *$ & .07 & .01 & $<1$ & 0 & ns \\
\hline $\mathrm{S} \times \mathrm{A}$ & 1 & $<1$ & 0 & ns & $<1$ & .01 & ns \\
\hline $\mathrm{S} \times \mathrm{SP} \times \mathrm{A}$ & 1 & $<1$ & .01 & ns & $<1$ & 0 & ns \\
\hline$P$ within-group error & 101 & $(1.81)$ & & & $(.90)$ & & \\
\hline
\end{tabular}

Note: Values enclosed in parentheses represent mean square errors; $P=$ participants

$* * p<.01, * * * p<.001$

A 2 (Sex) $\times 2$ (Attractiveness) $\times 2$ (Status) ANOVA for pen playing revealed a significant Status $\times$ Sex interaction. Separate $t$-tests for men and women showed a more frequent imitation of pen playing by women in the high status condition $(M=1.38, S D=1.55)$ than women in the low status condition $(M=.41, \quad S D=.80), \quad t(51)=2.90, \quad p<.01$. However, for men, no effect of status was found.

A 2 (Sex) $\times 2$ (Attractiveness) $\times 2$ (Status) ANOVA for changes of posture revealed an Attractiveness $\times$ Sex interaction. $T$-tests showed that men imitated the confederate's posture changes much more frequently in the high attractiveness condition $(M=1.07, S D=1.29)$ than in the low attractiveness condition $(M=.29, S D=.44), t(54)=3.05$, $p<.01$. The difference for women was not significant.

In summary, only men seemed to adjust their posture to highly attractive interaction partners. Correlations were consistent with this finding. For men, correlations of mimicry of pen playing with the reported desire to go on a date and to have sex were low, .05 and .07 , respectively ( $p$ s > .20 ), as compared to significant correlations for the frequency of mimicry of posture change, .29 and .33 ( $p$ s < $.05)$. Correlations for female desire to go on a date to have sex were with mimicry of pen playing were .18 and .04 respectively, compared to -.15 and .03 for posture change (all $p \mathrm{~s}>.20$ ).

\section{Discussion}

The research on STM of the last decades has been dominated by correlational studies and experiments using vignettes. In this study, our purpose was to further qualify the recurrently highlighted main sex difference in the intensity of STM-desire by using a more ecologically and internally valid paradigm. We experimentally investigated the effect of low and high levels of physical attractiveness and social status of an opposite sex confederate on the strength of the STM-desire single participants report toward this person. Importantly, participants spent about $20 \mathrm{~min}$ with the confederate, which increased the realism of the 
questions about the confederate. As expected, men reported a higher level of STM-desire than women, but only when the female confederate was attractive. This sex difference has been found previously solely using ratings (e.g., Buss \& Schmitt, 1993) and vignettes with respectively absent and fictive targets. This is the first time it is reported in an experimental design using real persons as targets. It is also important to note that men and women did not differ in their level of reported STM-desire toward the low attractive confederate. These results exemplify that statements like “men's standards for STM typically drop so low that they're willing to copulate with pretty much anything that is selfmoving..." (Buller, 2005, p. 208) ignore the variability and context dependency of male mate selection criteria.

For women, status and attractiveness manipulations had little effect on their reported STM-desires towards the targets. Hence, the preferences of women for STM-characteristics were more difficult to identify from these results than those of men. An explanation for the lack of effect of the characteristics that were hypothesized to be of importance is that women are highly selective in mate choice (e.g., Regan, 1998) and might pursue a threshold strategy (e.g., Townsend, 1993; Townsend \& Wasserman, 1998). Thus, a target with high physical attractiveness and social status might still not reach the threshold to become a desirable STM-partner. Additionally, extensive interaction might be important for characteristics to affect the STM-desirability of a man.

In addition to these self-reports of STM-desire, we observed the amount of mimicry men and women displayed, because mimicry is considered a product of interpersonal liking and motivations to affiliate (Bernieri \& Rosenthal, 1991; Lakin \& Chartrand, 2003). Although it was not our main goal, we believe the results provide us with valuable information about underlying preferences. The male pattern of frequencies of mimicry was consistent with the pattern of reported STM-desire. That is, men displayed more mimicry when the confederate was attractive than when she was not. Women, however, mimicked more frequently when the confederate was high in social status. So, women's uncontrollable and automatic interpersonal behaviors fit with a strategy that is aimed at the assessment of a long-term mate, a goal, which attaches more importance to status than to physical attractiveness (e.g., Buss, 1989).

It is difficult to tie mimicry directly to STM-desire, but research has shown it to be a subtle means through which people communicate liking (Bernieri \& Rosenthal, 1991; LaFrance, 1979; Lakin \& Chartrand, 2003). The current results, therefore, are promising. The correlations of selfreport measures of STM-desire with the frequency of mimicry were low, especially for women. Hence, we might have been observing an independent system, communicating unconscious liking. Mimicry occurs predominantly outside of awareness (Chartrand \& Bargh, 1999), which makes it susceptible to innate or instinctive responses that do not reach the awareness levels necessary to report on. Future research should further investigate the role of mimicry as a product of mating intentions. It would be interesting, for example, to investigate mimicry of participants who are presented with a confederate indicating sexual interest very subtly. Furthermore, adding coding of courtship behaviors, as investigated intensively by Moore (1985) and Grammer (1990; Grammer, Kruck, \& Magnusson, 1998), in a context that allows more interaction, would be very informative in terms of the communication of STM intentions. Furthermore, possible influential characteristics of the participants, such as their own physical attractiveness and social status, but also previous STM-experience and attachment styles (e.g., Hazan \& Diamond, 2000), would be appealing to investigate.

Using real targets has some limitations that warrant consideration. Most importantly, there is the risk of confound of the characteristics at stake with other characteristics. For example, physical attractiveness has been found to correlate positively with social skills (Langlois et al., 2000). We prevented this possible confound by minimizing the actual interaction. Moreover, confederates' social behavior was standardized by extensive training. Because of this procedure, the influence of individual differences in social skills on participants was minimized. This is one of the major advantages of the use of trained confederates over the studies that used pairings of regular participants (Berry \& Miller, 2001; Garcia et al., 1991). In addition, the credibility of the situation should be given a great amount of attention. Even naturalistic environments potentially lead to specific demand characteristics, because they differ so much from usual research settings. We attempted to minimize demand characteristics by providing a clear cover story, but still two participants indicated doubts. Carefully checking the credibility of the lab situation remains highly important when using confederates and special laboratories.

The use of confederates in a naturalistic setting enhances the level of realism of the experiment. Therefore, the current results rely on a high degree of ecological validity. As a validation of survey and vignette studies on STM, the current study provided an important test of the hypotheses. We are convinced that areas of research that rely heavily on vignettes or ratings, both in and outside the field of human mating, would benefit from the use of both confederates and a naturalistic environment. Using this paradigm is relatively time consuming, which might make researchers reluctant to do so. However, if somehow doubts exist about the degree to which participants can project themselves into the requested situation, the current approach is indispensable. 
Acknowledgment Parts of this article were presented at the 7th Annual Meeting of the Society for Personality and Social Psychology, Palm Springs, California, January 2006.

\section{References}

Baldwin, J. D., \& Baldwin, J. I. (1988). Factors affecting AIDS-related sexual risk-taking behavior among college students. Journal of Sex Research, 25, 181-196.

Baumeister, R. F., Catanese, K. R., \& Vohs, K. D. (2001). Is there a gender difference in strength of sex drive? Theoretical views, conceptual distinctions, and a review of relevant evidence. Personality and Social Psychology Review, 5, 242-273.

Bernieri, F. J., \& Rosenthal, R. (1991). Interpersonal coordination: Behavior matching and interactional synchrony. In R. S. Feldman \& B. Rime (Eds.), Fundamentals of nonverbal behavior (pp. 401432). New York: Cambridge University Press.

Berry, D. S., \& Miller, K. M. (2001). When boy meets girl: Attractiveness and the five-factor model in opposite-sex interactions. Journal of Research in Personality, 35, 62-77.

Bot, S. M., Engels, R. C. M. E., \& Knibbe, R. A. (2005). The effects of alcohol expectancies on drinking behaviour in peer groups: Observations in a naturalistic setting. Addiction, 100, 1270-1279.

Brown, N. R., \& Sinclair, R. C. (1999). Estimating number of lifetime sexual partners: Men and women do it differently. Journal of Sex Research, 36, 292-297.

Buller, D. J. (2005). Adapting minds: Evolutionary psychology and the persistent quest for human nature. Cambridge, MA: MIT Press.

Buss, D. M. (1989). Sex differences in human mate preferences: Evolutionary hypotheses tested in 37 cultures. Behavioral and Brain Sciences, 12, 1-49.

Buss, D. M., \& Schmitt, D. P. (1993). Sexual strategies theory: An evolutionary perspective on human mating. Psychological Review, 100, 204-232.

Chartrand, T. L., \& Bargh, J. A. (1999). The chameleon effect: The perception-behavior link and social interaction. Journal of Personality and Social Psychology, 76, 893-910.

Clark, R. D. (1990). The impact of AIDS on gender differences in willingness to engage in casual sex. Journal of Applied Social Psychology, 20, 771-782.

Clark, R. D., \& Hatfield, E. (1989). Gender differences in receptivity to sexual offers. Journal of Psychology and Human Sexuality, 2, 3955 .

Cubbins, L. A., \& Tanfer, K. (2000). The influence of gender on sex: A study of men's and women's self-reported high-risk sex behavior. Archives of Sexual Behavior, 29, 229-257.

Gangestad, S. W., \& Simpson, J. A. (1990). Toward an evolutionary history of female sociosexual variation. Journal of Personality, $58,69-96$.

Gangestad, S. W., \& Simpson, J. A. (2000). The evolution of human mating: Trade-offs and strategic pluralism. Behavioral and Brain Sciences, 23, 573-644.

Garcia, S., Stinson, L., Ickes, W., Bissonnette, V., \& Briggs, S. (1991). Shyness and physical attractiveness in mixed-sex dyads. Journal of Personality and Social Psychology, 61, 35-49.

Grammer, K. (1990). Strangers meet: Laughter and nonverbal signs of interest in opposite-sex encounters. Journal of Nonverbal Behavior, 14, 209-236.

Grammer, K., Kruck, K. B., \& Magnusson, M. S. (1998). The courtship dance: Patterns of nonverbal synchronization in opposite-sex encounters. Journal of Nonverbal Behavior, 22, 3-29.

Greiling, H., \& Buss, D. M. (2000). Women's sexual strategies: The hidden dimension of extra-pair mating. Personality and Individual Differences, 28, 929-963.
Greitemeyer, T. (2005). Receptivity to sexual offers as a function of sex, socioeconomic status, physical attractiveness, and intimacy of the offer. Personal Relationships, 12, 373-386.

Hazan, C., \& Diamond, L. M. (2000). The place of attachment in human mating. Review of General Psychology, 4, 186-204.

Herold, E. S., \& Mewhinney, D. M. K. (1993). Gender differences in casual sex and AIDS prevention: A survey of dating bars. Journal of Sex Research, 30, 36-42.

Hrdy, S. B. (1981). The woman that never evolved. Cambridge, MA: Harvard University Press.

Johnson, A. M., Mercer, C. H., Erens, B., Copas, A. J., McManus, S., Wellings, K., et al. (2001). Sexual behaviour in Britain: Partnerships, practices, and HIV risk behaviours. Lancet, 358, 18351842.

LaFrance, M. (1979). Nonverbal synchrony and rapport: Analysis by the cross-lag panel technique. Social Psychology Quarterly, 42, 66-70.

Lakin, J. L., \& Chartrand, T. L. (2003). Using nonconscious behavioral mimicry to create affiliation and rapport. Psychological Science, 14, 334-339.

Langlois, J. H., Kalakanis, L., Rubenstein, A. J., Larson, A., Hallam, M., \& Smoot, M. (2000). Maxims or myths of beauty? A metaanalytic and theoretical review. Psychological Bulletin, 126, 390423.

Laumann, E. O., Gagnon, J. H., Michael, R. T., \& Michaels, S. (1994). The social organization of sexuality: Sexual practices in the United States. Chicago: University of Chicago Press.

Maxwell, G. M., Cook, M. W., \& Burr, R. (1985). The encoding and decoding of liking from behavioral cues in both auditory and visual channels. Journal of Nonverbal Behavior, 9, 239-263.

Moore, M. M. (1985). Nonverbal courtship patterns in women: Context and consequences. Ethology and Sociobiology, 6, 237-247.

Oliver, M. B., \& Hyde, J. S. (1993). Gender differences in sexuality: A meta-analysis. Psychological Bulletin, 114, 29-51.

Pedersen, W. C., Miller, L. C., Putcha-Bhagavatula, A. D., \& Yang, Y. (2002). Evolved sex differences in the number of partners desired? The long and short of it. Psychological Science, 13, 157-161.

Regan, P. C. (1998). Minimum mate selection standards as a function of perceived mate value, relationship context, and gender. Journal of Psychology and Human Sexuality, 10, 53-73.

Regan, P. C., \& Dreyer, C. S. (1999). Lust? Love? Status? Young adults' motives for engaging in casual sex. Journal of Psychology and Human Sexuality, 11, 1-24.

Roche, J. P. (1986). Premarital sex: Attitudes and behavior by dating stage. Adolescence, 21, 107-121.

Rocheleau, C. A., Webster, G. D., Bryan, A., \& Frazier, J. (2004). Moderators of the relationship between exercise and mood changes: Gender, exertion level, and workout duration. Psychology and Health, 19, 491-506.

Shackelford, T. K., Goetz, A. T., LaMunyon, C. W., Quintus, B. J., \& Weekes-Shackelford, V. A. (2004). Sex differences in sexual psychology produce sex-similar preferences for a short-term mate. Archives of Sexual Behavior, 33, 405-412.

Smith, R. L. (1984). Human sperm competition. In R. L. Smith (Ed.), Sperm competition and the evolution of mating systems (pp. 601659). New York: Academic Press.

Sprecher, S., \& Regan, P. C. (2002). Liking some things (in some people) more than others: Partner preferences in romantic relationships and friendships. Journal of Social and Personal Relationships, 19, 463-481.

Symons, D. (1979). The evolution of human sexuality. New York: Oxford University Press.

Townsend, J. M. (1993). Sexuality and partner selection: Sex differences among college students. Ethology and Sociobiology, $14,305-329$. 
Townsend, J. M. (1995). Sex without emotional involvement: An evolutionary interpretation of sex differences. Archives of Sexual Behavior, 24, 173-206.

Townsend, J. M., \& Levy, G. D. (1990). Effects of potential partners' physical attractiveness and socioeconomic status on sexuality and partner selection. Archives of Sexual Behavior, 19, 149-164.

Townsend, J. M., \& Wasserman, T. (1998). Sexual attractiveness: Sex differences in assessment and criteria. Evolution and Human Behavior, 19, 171-191.

Traeen, B., \& Lewin, B. (1992). Casual sex among Norwegian adolescents. Archives of Sexual Behavior, 21, 253-269.
Trivers, R. L. (1972). Parental investment and sexual selection. In B. Campbell (Ed.), Sexual selection and the descent of man (pp. 136179). New York: Aldine de Gruyter.

Webb, E. J., Campbell, D. T., Schwartz, R. D., \& Sechrest, L. (1966). Unobtrusive measures: Nonreactive research in the social sciences. Chicago: Rand McNally \& Company.

Wiederman, M. W. (1997). Extramarital sex: Prevalence and correlates in a national survey. Journal of Sex Research, 34, 167-174.

Wiederman, M. W., \& Dubois, S. L. (1998). Evolution and sex differences in preferences for short-term mates: Results from a policy capturing study. Evolution and Human Behavior, 19, 153170. 